\title{
Acute Kidney Injury due to Crescentic Glomerulonephritis in a Patient with Polycystic Kidney Disease
}

\author{
Reuben Maggard $^{\mathrm{a}} \quad$ Raafat Makary $^{\mathrm{b}}$ Carmela I. Monteiro $^{\mathrm{b}}$ \\ Leighton R. James ${ }^{a}$ \\ ${ }^{a}$ Division of Nephrology and Hypertension, Department of Medicine, and ${ }^{b}$ Department of \\ Pathology and Laboratory Medicine, University of Florida, Jacksonville, Fla., USA
}

Key Words

Crescentic glomerulonephritis · Polycystic kidney disease · Acute kidney injury

\begin{abstract}
Polycystic kidney disease is an inherited condition, characterized by the development of cysts in the kidney, as well as in other organs. Patients with polycystic kidney can suffer from the same causes of acute kidney injury as the general population. Nephritic syndrome is an uncommon cause of acute kidney injury in the general population and less common in patients with polycystic kidney disease. We report the second case of crescentic glomerulonephritis, causing acute kidney injury, in a patient with polycystic kidney disease.
\end{abstract}

(c) 2013 S. Karger AG, Basel

\section{Introduction}

Polycystic kidney disease (PKD) is the most common cause of monogenic inherited kidney disease and is associated with extrarenal manifestation of cystogenesis in other organs including liver and pancreas, saccular aneurysm in central nervous system vasculature and mitral valve disease [1]. The genetic basis for this has been identified as mutations in one of two large proteins, polycystin 1 and 2 [for review, please refer to references 2, 3]. The penetrance is highly variable in that cysts and chronic kidney disease may develop at different ages within the same family with identical mutation. The reasons for this are unclear and various hypotheses have been advanced to address this observation [4-6]. In 
addition to cyst formation, manifestation of kidney disease includes subnephrotic proteinuria, microscopic and macroscopic hematuria; nephrotic-range proteinuria ( $>3 \mathrm{~g} / \mathrm{day}$ ) is uncommon. Acute renal failure secondary to rapidly progressive glomerulonephritis is rare and, thus far, only 1 case has been described [7]. We report a case of crescent, rapidly progressive glomerulonephritis in a patient with PKD.

\section{Case Report}

A 43-year-old man presented to the emergency department complaining of lower extremity edema for 2 weeks. The patient denied any pertinent past medical or family medical history; though he took metoprolol and hydrochlorthiazide for about 1 month a year earlier, he was not taking either of these agents at the time of presentation. He denied use of nonsteroidal anti-inflammatory agents and recreational drugs (including cocaine, heroin and phencyclidine). Initial physical examination was significant for elevated blood pressure (151/94 mm Hg) and pitting edema in both lower extremities. Initial laboratory analysis at presentation (table 1) revealed renal failure (serum creatinine $2.6 \mathrm{mg} / \mathrm{dl}$ ) and anemia (hemoglobin $10.8 \mathrm{~g} / \mathrm{dl}$, hematocrit $33.4 \%$ and mean corpuscular volume $85.4 \mathrm{fl}$ ). Urinalysis (random urine; table 2) showed proteinuria, small blood and pyuria without bacteria. Proteinuria was confirmed on 24-hour urine collection that demonstrated nephrotic-range protein $(25 \mathrm{~g} / 24 \mathrm{~h})$. Kidney ultrasound revealed enlarged kidneys bilaterally with multiple cysts and this was confirmed by computed tomography (CT) scanning (fig. 1a). A complete serologic evaluation, including hepatitis screen, was performed and was unrevealing (table 2).

Initially, the patient was empirically treated with intravenous steroid pulse (methylprednisolone, $1 \mathrm{~g}$ daily for 3 days) and then switched to prednisone orally (1 mg per kilogram daily). A CT-guided kidney biopsy was performed and revealed immune complex glomerulonephritis with features of membranous nephropathy with crescent formation (fig. 1b). Despite treatment with oral prednisone $(1 \mathrm{mg} / \mathrm{kg})$, the patient's renal function declined and he became oliguric. Intermittent hemodialysis was initiated. In addition to oral steroid, treatment with mycophenolate $(500 \mathrm{mg}$ twice daily; escalated to 1,500 mg twice daily over 2 weeks) was started. Over a 5-month period, urine output increased in association with improvement in kidney function. Concurrently, serum albumin recovered to normal values and proteinuria decreased from 25 to $3 \mathrm{~g}$ daily. Because of persistent nephrotic-range proteinuria, cyclosporine $75 \mathrm{mg}$ twice daily was added to his medication regimen. Over the ensuing 3 months, the patient manifested further improvement in physiologic parameters. Accordingly, prednisone dosage was reduced (10 mg orally per day) and mycophenolate mofetil (MMF) was maintained at 1,500 mg orally twice daily and cyclosporine at $75 \mathrm{mg}$ orally twice daily. Hemodialysis was subsequently discontinued and the patient has been off dialysis with stable chronic kidney disease stage 3 (creatinine clearance $45 \mathrm{ml} / \mathrm{min}$ by 24hour urine studies). He continues to be monitored closely in an outpatient setting for any changes in renal function. Immunosuppressive agents are being tapered.

\section{Discussion}

In patients with autosomal dominant polycystic kidney disease (ADPKD), nephroticrange proteinuria is an uncommon occurrence. However, when this has been reported, various etiologies have been identified, including membranous glomerulonephritis, focal and 
segmental glomerulosclerosis, minimal change disease [8-10] and immunoglobulin A (IgA) nephropathy $[11,12]$. Of these, focal and segmental glomerulosclerosis appears to be the most frequently reported cause of nephrotic-range proteinuria in those with ADPKD who develop proteinuria $[8,13]$. Proliferative glomerulonephritis, including IgA nephropathy, is a less common cause of nephrotic syndrome [11,14]. Crescentic glomerulonephritis is a rare occurrence in those with PKD and has only been reported once in the literature [7]. All reported series emphasize the importance of performing kidney biopsies in patients with PKD who develop nephrotic-range proteinuria. In addition to identifying the cause of massive proteinuria in this population, renal biopsy informs appropriate management of proteinuria in affected individuals.

In the current case, the cause of acute kidney injury and nephrotic syndrome was identified as crescentic glomerulonephritis rather that the patient's underlying PKD. In addition, the findings on biopsy were important in guiding a more aggressive immunosuppressive regimen in the management of the patient. The reason(s) for the occurrence of glomerulopathies, with massive proteinuria, in ADPKD remain unclear. In the current case, common causes of rapidly progressive kidney failure and nephrotic-range proteinuria, including postinfectious causes, hepatitis B and C and IgA nephropathy were excluded.

Given the rarity of rapidly progressive crescent glomerulonephritis in those with PKD, there are no established guidelines on management. Because PKD in this patient was diagnosed on this presentation and in view of rapidly progressive glomerulonephritis, management of the latter is the primary goal. The combination of steroid and MMF was chosen over steroids and cyclophosphamide because of a better side effect profile. Cyclosporine was added to enhance management of proteinuria. The patient has responded favorable to a combination of steroids, MMF and cyclosporine. This case also illustrates the importance of a prompt diagnosis of nephritic syndrome in patients with PKD, especially when there is an acute deterioration of kidney function, information that cannot be obtained from conventional imaging and serologic analyses.

\section{Disclosure Statement}

The authors declare no conflicts of interest.

\section{References}

1 Igarashi P, Somlo S: Polycystic kidney disease. J Am Soc Nephrol 2007;18:1371-1373.

-2 Boucher C, Sandford R: Autosomal dominant polycystic kidney disease (ADPKD, MIM 173900, PKD1 and PKD2 genes, protein products known as polycystin-1 and polycystin-2). Eur J Hum Genet 2004;12:347-354.

-3 Igarashi P, Somlo S: Genetics and pathogenesis of polycystic kidney disease. J Am Soc Nephrol 2002;13:2384-2398.

4 Pei Y: A 'two-hit' model of cystogenesis in autosomal dominant polycystic kidney disease? Trends Mol Med 2001;7:151-156.

5 Takakura A, Contrino L, Beck AW, Zhou J: Pkd1 inactivation induced in adulthood produces focal cystic disease. J Am Soc Nephrol 2008;19:2351-2363.

6 Takakura A, Contrino L, Zhou X, Bonventre JV, Sun Y, Humphreys BD, Zhou J: Renal injury is a third hit promoting rapid development of adult polycystic kidney disease. Hum Mol Genet 2009;18:2523-2531.

7 Licina MG, Adler S, Bruns FJ: Acute renal failure in a patient with polycystic kidney disease. JAMA 1981;245:1664-1665.

-8 Contreras G, Mercado A, Pardo V, Vaamonde CA: Nephrotic syndrome in autosomal dominant polycystic kidney disease. J Am Soc Nephrol 1995;6:1354-1359. 
Maggard et al:: Acute Kidney Injury due to Crescentic Glomerulonephritis in a Patient with Polycystic Kidney Disease

9 Peces R, Martinez-Ara J, Peces C, Picazo M, Cuesta-Lopez E, Vega C, Azorin S, Selgas R: Nephrotic syndrome and idiopathic membranous nephropathy associated with autosomal-dominant polycystic kidney disease. Scientific World Journal 2011;11:1041-1047.

10 Savaj S, Parvin M, Savoj J: Massive proteinuria and autosomal dominant polycystic kidney disease: a rare coincidence. Iran J Kidney Dis 2012;6:73-76.

11 Hiura T, Yamazaki H, Saeki T, Kawabe S, Ueno M, Nishi S, Miyamura S, Gejyo F: Nephrotic syndrome and IgA nephropathy in polycystic kidney disease. Clin Exp Nephrol 2006;10:136-139.

12 Panisello JM, Martinez-Vea A, Garcia C, Carrera M, Oliver JA, Richart C: IgA nephropathy and polycystic kidney disease. Am J Nephrol 1988;8:477-478.

13 Montoyo C, Martinez MA, Campo C, Mazuecos A, Andres A, Praga M: Nephrotic syndrome and focal glomerulosclerosis in adult polycystic kidney disease. Nephron 1992;61:106-110.

14 D’Cruz S, Singh R, Mohan H, Kaur R, Minz RW, Kapoor V, Sachdev A: Autosomal dominant polycystic kidney disease with diffuse proliferative glomerulonephritis - an unusual association: a case report and review of the literature. J Med Case Rep 2010;4:125.

Table 1. Initial laboratory data at presentation

\begin{tabular}{lcc}
\hline & & Reference range \\
\hline Sodium, mmol/l & 137 & $135-145$ \\
Potassium, mmol/l & 3.3 & $3.5-5.0$ \\
Chloride, mmol/l & 104 & $101-110$ \\
Carbon dioxide, mmol/l & 29 & $21-0.29$ \\
Glucose, mg/dl & 79 & $71-99$ \\
BUN, mg/dl & 26 & $6-22$ \\
Creatinine, mg/dl & 2.6 & $0.51-0.95$ \\
Albumin, g/dl & 1.6 & $3.8-4.9$ \\
AST, U/l & 20 & $10-42$ \\
ALT, U/l & 12 & $14-33$ \\
Alkaline phosphate, $\mathrm{U} / \mathrm{l}$ & 40 & $40-129$ \\
\hline ProBNP, pg/ml & 115.7 & $0-125$ \\
Cardiac CK, $\mathrm{U} / \mathrm{l}$ & 145 & $22-195$ \\
\hline White blood cells, $\times 10^{3} / \mu \mathrm{l}$ & 6.3 & $4.5-11.0$ \\
Hemoglobin, g/dl & 10.8 & $14.0-18.0$ \\
Hematocrit, \% & 33.4 & $40.0-54.0$ \\
MCV, fl & 85.4 & $82.0-101.0$ \\
Platelets, $\times 10^{3} / \mu \mathrm{l}$ & 314 & $140-440$ \\
\hline
\end{tabular}

AST = Aspartate aminotransferase; ALT = alanine transaminase; BUN = blood urea nitrogen; ProBNP = pro-B-type natriuretic peptide; $\mathrm{CK}=$ creatine kinase. 
Maggard et al:: Acute Kidney Injury due to Crescentic Glomerulonephritis in a Patient with Polycystic Kidney Disease

Table 2. Initial urinalysis and serologic findings

\begin{tabular}{|c|c|c|}
\hline & & Reference range \\
\hline \multicolumn{3}{|l|}{ Urinalysis } \\
\hline Specific gravity & 1.018 & $1.003-1.030$ \\
\hline $\mathrm{pH}$ & 7.0 & $4.5-8.0$ \\
\hline Protein & $2,000 \mathrm{mg} / \mathrm{dl}$ & Negative \\
\hline Glucose & Negative & Negative \\
\hline Blood & Small & Negative \\
\hline Leukocyte esterase & Negative & Negative \\
\hline Nitrites & Negative & Negative \\
\hline Red blood cells & 39/hpf & $0-5 / \mathrm{hpf}$ \\
\hline White blood cells & $13 / \mathrm{hpf}$ & $0-5 / \mathrm{hpf}$ \\
\hline Bacteria & None seen & None \\
\hline Casts & None seen & None \\
\hline \multicolumn{3}{|l|}{ Serologies } \\
\hline HIV-1/HIV-2 & Not detected & \\
\hline Hepatitis BsAg & Not detected & \\
\hline Hepatitis BsAg antibody & Not detected & \\
\hline Hepatitis C antibody & Not detected & \\
\hline p-ANCA & $<1: 20$ & \\
\hline c-ANCA & $<1: 20$ & \\
\hline Anti-GBM antibody & 3 & $0-20$ \\
\hline Cryoglobulin & Not detected & \\
\hline Complement, C3 & 80 & $90-120$ \\
\hline Complement, C4 & 26 & $10-40$ \\
\hline \multicolumn{3}{|l|}{ Anti-streptolysin } \\
\hline ANA & Not detected & \\
\hline Anti-dsDNA antibody & Not detected & \\
\hline Anti-Smith antibody & Not detected & \\
\hline RNP antibody & $<0.2$ & $0.0-0.9$ \\
\hline Serum protein electrophoresis & No abnormal proteins detected & \\
\hline Urine protein electrophoresis & No abnormal proteins detected & \\
\hline
\end{tabular}




\section{Case Reports in \\ Nephrology and Urology}

\begin{tabular}{l|l}
\hline Case Rep Nephrol Urol 2013;3:99-104 \\
\hline DOI: 10.1159/000353850 & $\begin{array}{l}\text { ○ 2013 S. Karger AG, Basel } \\
\text { www.karger.com/cru }\end{array}$ \\
\hline
\end{tabular}

Maggard et al.: Acute Kidney Injury due to Crescentic Glomerulonephritis in a Patient with Polycystic Kidney Disease

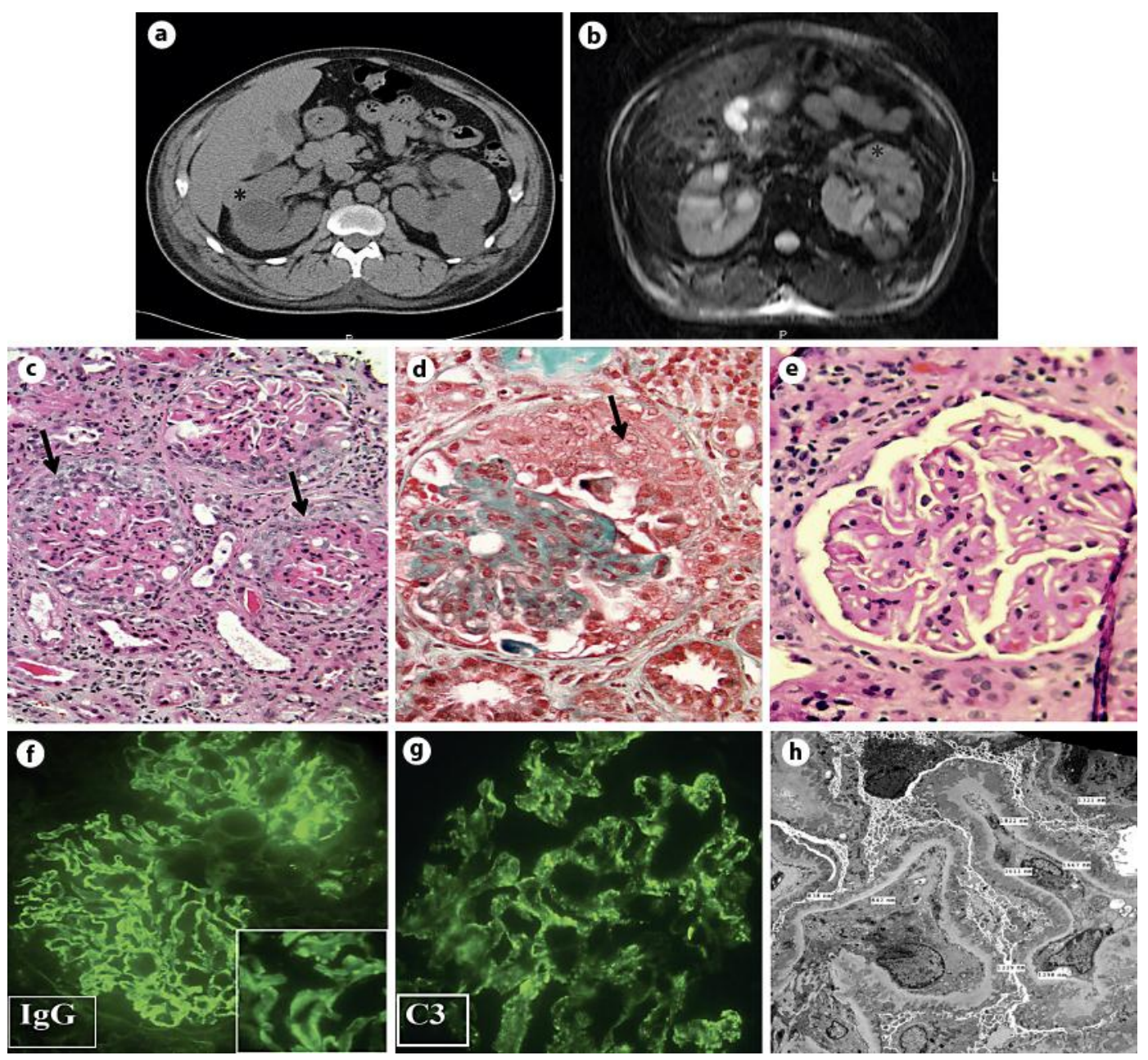

Fig. 1. Abdominal CT without intravenous contrast $(\mathbf{a}, \mathbf{b})$ reveals multiple simple cysts $(*)$; some cysts with increased density are believed to represent proteinaceous or possible hemorrhagic cysts. Several glomeruli depict crescent formation (arrows; c HE, 10×; d Gömöri trichrome stain, 40×) with prominent glomerular basement membrane thickening (e HE, 40x). Immunofluorescence shows positive granular immune deposits (f IgG; inset high magnification; g C3). Ultrastructural imaging shows markedly thickened glomerular basement membrane with numerous subepithelial electron-dense deposits (h electron microscopy, $1,900 \times$ ). 